\title{
STUDY OF SHOULDER FUNCTION AND UNION RATES OF CLAVICLE HOOK PLATING IN TYPE II NEER FRACTURES
}

\author{
Vivek Kumar ${ }^{1}$, Abhinav Bhardwaj², Seema ${ }^{3}$, Anas Shaikh ${ }^{4}$, Raj Parmar ${ }^{5}$, Vikram Jasoliya ${ }^{6}$, Janak Rathod ${ }^{7}$
}

1 Junior Resident, Department of Orthopaedics, SMIMER, Surat.

2Junior Resident, Department of Medicine, MMIMSR, Ambala.

${ }_{3}^{3}$ Senior Resident, Department of OBG, PGIMS, Rohtak.

4Junior Resident, Department of Orthopaedics, SMIMER, Surat.

5Junior Resident, Department of Orthopaedics, SMIMER, Surat.

${ }^{6}$ Assistant Professor, Department of Orthopaedics, SMIMER, Surat.

${ }^{7}$ Associate Professor, Department of Orthopaedics, SMIMER, Surat.

\section{ABSTRACT}

\section{BACKGROUND}

Fracture of the clavicle accounts for approximately 5 to $10 \%$ of all the fractures and up to $44 \%$ of injuries to the shoulder girdle. Surgical treatment has been recommended for Neer type II clavicle fractures. About $70 \%$ to $80 \%$ of these fractures are in the middle third of the bone and less often in the lateral third (18\% to $25 \%)$ and medial third (5\% to 6\%). In surgical procedures, clavicular hook plate fixation with an extension under the acromion, which provides more rigid fixation and good bony union rates.

The aim of study is to evaluate shoulder function and union rate and long-term effects of clavicle hook plate fixation for Neer type II distal clavicle fractures.

\section{MATERIALS AND METHODS}

The study was a case series study and was conducted for period between November 2014 to April 2016. The treatment of distal third clavicle fractures by using clavicle hook plates in 32 patients.

\section{RESULTS}

Fracture clavicle is common in young males. Mostly cause of fracture is road traffic accidents. Clavicle hook plate fixation with an extension under the acromion provides more rigid fixation and good bony union rates. It is associated with fewer complications and early mobilisation.

\section{CONCLUSION}

Clavicle hook plates are better surgical method of treatment of distal third clavicular fractures. It provides good short term as well as midterm results. Rarely using this plate may cause impingement and subacromial osteolysis without leading to functional impairment. These complications can be minimised by verification under fluoroscopy.

\section{KEYWORDS}

Clavicle, Hook Plate, Neer Type II Fracture.

HOW TO CITE THIS ARTICLE: Kumar V, Bhardwaj A, Seema, et al. Study of shoulder function and union rates of clavicle hook plating in type II Neer fractures. J. Evolution Med. Dent. Sci. 2017;6(73):5253-5256, DOI: 10.14260/Jemds/2017/1140

\section{BACKGROUND}

Fracture of the clavicle accounts for approximately 5 to $10 \%$ of all the fractures and up to $44 \%$ of injuries to the shoulder girdle. About $70 \%$ to $80 \%$ of these fractures are in the middle third of the bone and less often in the lateral third $(18 \%$ to $25 \%$ ) and medial third (5\% to $6 \%)^{1}$

Fractures of the lateral end of clavicle have been traditionally treated nonoperatively in form of sling, figure-of4 bandage with sling arm pouch. Although, many methods of closed reduction have been described, it is recognised that reduction is practically impossible to maintain and a certain amount of deformity and disability is expected in adults. ${ }^{1}$

Distal clavicle fractures account for approximately $21 \%$ of all clavicle fractures. ${ }^{2}$ Three types have been demonstrated

Financial or Other, Competing Interest: None.

Submission 13-06-2017, Peer Review 25-08-2017,

Acceptance 01-09-2017, Published 11-09-2017.

Corresponding Author:

Dr. Vivek Kumar,

H. N. 09, Vikas Nagar,

Bhiwani-127021, Haryana.

E-mail: vivekbhardwaj8@gmail.com

DOI: $10.14260 /$ jemds $/ 2017 / 1140$ based on the relationship of the fracture line to the coracoclavicular ligaments and acromioclavicular joint. ${ }^{3}$ Neer type I fractures and Neer type III fractures are stable with minimal displacement because the proximal fragment is stabilised by the coracoclavicular ligaments and they are usually treated with nonsurgical techniques Neer type II fractures occur more medial to the coracoclavicular ligaments and often result in major displacement because of complete or incomplete rupture of the coracoclavicular ligaments resulting in higher rates of nonunion ranging from $21 \%$ to $44 \%$ with nonsurgical management.(4-5) Surgical treatment has been recommended for Neer type II fractures. ${ }^{6}$

There are various surgical procedures used for Neer type II clavicle fractures-

1. Transacromial Kirschner wires.

2. Knowles pins.

3. Weaver-Dunn procedure.

4. Tension band wires.

5. Coracoclavicular screw fixation.

6. Plate fixation.

7. Arthroscopic treatment, etc. 
Despites of these many surgical procedures, no one of these is generally regarded as the gold standard treatment. Nowadays, clavicular hook plate fixation with an extension under the acromion, which provides more rigid fixation and good bony union rates is considered as a better surgical method. The proponents of fixation of lateral end clavicle fractures to prevent complications like malunion and nonunion emphasise the value of accurate reduction and rigid fixation with quicker pain relief and promoting early functional recovery. Prevalence of delayed union has been reported between $45 \%-66 \%$ and with nonunion in $22 \%-33 \%$. Because of these high incidences, primary surgical stabilisation advised in all displaced lateral end fractures.

\section{MATERIALS AND METHODS}

It was case series study. The purpose of this study was to evaluate the clinical and radiographic results in terms of shoulder function and union rate and long-term effects of clavicular hook plate fixation for Neer type II distal clavicular fractures.

The present study was carried at tertiary care hospital. During this period, 32 patients of lateral end clavicle fractures treated with open reduction and internal fixation with hook plate. The study was conducted for a period between November 2014 to April 2016. The treatment of distal third clavicle fractures in based on their classification. It includes nonoperative with sling immobilisation and progressive use of shoulder as pain allows and operative treatment as transacromial or distal end of clavicle Kirschner wire with or without tension band wiring, coracoclavicular screw plate fixation.

\section{Inclusion Criteria}

- Adult patients above 18 years who had lateral end clavicle fracture (Neer type 2) were included for this study after taking written consent from them. Patients with Neer type II distal clavicle fractures treated in our hospital between 2014 and 2016 were included in study.

- Normal shoulder function before injury.

\section{Exclusion Criteria}

- Patients lost to postoperative follow-up with acromioclavicular joint dislocation.

- Pathologic fractures.

- Previous surgery on the affected clavicle or shoulder.

- Patients with incomplete data were excluded.

- Patients unfit for surgery.

- Associated with neurovascular injury.

General information like name, age, sex, occupation and address were noted. Then, a detailed history was elicited regarding mode of injury like fall on the shoulder, road traffic accident, direct injury to shoulder and fall on outstretched hand. Enquiry was made to note site of pain and swelling over the affected clavicle. Past medical history and family history was also recorded. Patients for surgery were selected as per indications for surgery and patient's consent.

General condition of the patients was examined that is for pallor, pulse rate and blood pressure. Respiratory and cardiovascular system were examined for any abnormalities.
RESULTS

\begin{tabular}{|c|c|}
\hline No. of Patients & 32 \\
\hline No. of M:F & $24: 8$ \\
\hline Mean age (range) & 33.05 years (range 18-67) \\
\hline No. of right-left sides & $21: 11$ \\
\hline Mean followup (range) & $\begin{array}{c}24.10 \text { months (range 10-48 } \\
\text { months) }\end{array}$ \\
\hline No. of falling-MVA injuries & $41: 59$ \\
\hline $\begin{array}{c}\text { Mean time from injury to } \\
\text { surgery (range) }\end{array}$ & 4.13 days (range 2-10 days) \\
\hline \multicolumn{2}{|c|}{ Table 1. Demographic profile } \\
\hline
\end{tabular}

Mean age was 33.05 years (range 18-67), male-to-female ratio was 24 to 8 . Thirteen patients had a right-sided and 9 had a left-sided fracture. All patients had Neer type II fracture. Mean duration of hospital stay was 10.22 (range 6-16 days) and for all the patients rehabilitation started on $3^{\text {rd }}$ day postoperative. The mean follow up was 24.10 months (range 10-48 months). The plate was removed under general anaesthesia (16-36 weeks) with mean duration of 22.66 weeks for implant removal.

\begin{tabular}{|c|c|c|}
\hline Complication & $\begin{array}{c}\text { No. of } \\
\text { Patients }\end{array}$ & Treatment \\
\hline $\begin{array}{c}\text { Postoperative } \\
\text { Pain }\end{array}$ & 4 & $\begin{array}{c}\text { There was pain due to } \\
\text { impingement in 3 patients, which } \\
\text { was subsided after removal of } \\
\text { plate after 4 months }\end{array}$ \\
\hline $\begin{array}{c}\text { Subacromial } \\
\text { osteolysis }\end{array}$ & 2 & $\begin{array}{c}\text { The osteolysis was disappeared } \\
\text { after removal of plate }\end{array}$ \\
\hline Nonunion & 1 & $\begin{array}{c}\text { Though it was asymptomatic, } \\
\text { nonunion was because of } \\
\text { misplacement of hook plate }\end{array}$ \\
\hline $\begin{array}{c}\text { Wound } \\
\text { infection }\end{array}$ & 2 & $\begin{array}{c}\text { Infection was treated with } \\
\text { antibiotics }\end{array}$ \\
\hline \multicolumn{2}{|c|}{ Table 2. Short-Term Complications } \\
\hline
\end{tabular}

Short-term results and complications (Table 2)- During the outpatient clinic follow up, 2 patients were having subacromial osteolysis, 4 patients reported pain, 1 with nonunion and 2 with superficial wound infection. All fracture except one were clinically and radiologically united.

\begin{tabular}{|c|c|c|}
\hline ACJ arthrosis & Number & Treatment \\
\hline $\begin{array}{c}\text { Extra-articular } \\
\text { ossification }\end{array}$ & 3 & $\begin{array}{c}\text { Wne presented with } \\
\text { impingement and 2 were } \\
\text { asymptomatic }\end{array}$ \\
\hline Nonunion & 1 & $\begin{array}{c}\text { Causes of nonunion maybe the } \\
\text { risk factors associated with } \\
\text { patient. Old age (65 years), } \\
\text { smoking, hypertension }\end{array}$ \\
\hline $\begin{array}{c}\text { Mean Constant- } \\
\text { Murley score } \\
\text { (range) }\end{array}$ & $\begin{array}{c}97(78- \\
100)\end{array}$ & $\begin{array}{c}\text { The lowest Constant-Murley } \\
\text { score (78) }\end{array}$ \\
\hline \multicolumn{2}{|c|}{ Table 3. Mid-Term Results and Complications } \\
\hline
\end{tabular}

Mid-term results and complications (Table 3), the mean Constant-Murley score was 97 (78-100), a nonunion in one patient was confirmed radiographically. In one patient, ACJ arthrosis was observed. These patients had no symptoms. Only one of these patients with ACJ arthrosis had suffered impingement symptoms. 


\begin{tabular}{|c|c|c|}
\hline Gender & No. of Patients & Percentage (\%) \\
\hline Male & 24 & 75 \\
\hline Female & 8 & 25 \\
\hline \multicolumn{2}{|c|}{ Table 4. Gender Distribution of Study Group } \\
\hline
\end{tabular}

There were 24 males and 8 females in study.

\begin{tabular}{|c|c|c|}
\hline Mechanism of Injury & 32 Patients & \% \\
\hline Road traffic accident & 16 & 50 \\
\hline Direct injury to shoulder & 5 & 15.60 \\
\hline Fall on outstretched hand & 11 & 34.37 \\
\hline \multicolumn{2}{|c|}{ Table 5. Different Mechanism of Injury } \\
\hline
\end{tabular}

There were 16 road traffic accidents, 5 were direct injury on shoulder and 11 were fall on outstretched hand.

\begin{tabular}{|c|c|c|}
\hline Functional Outcome & Number of Patients & $\mathbf{\%}$ \\
\hline Excellent & 22 & 68.75 \\
\hline Good & 8 & 25 \\
\hline Fair & 2 & 6.25 \\
\hline \multicolumn{2}{|c|}{ Table 6. Functional Outcome } \\
\hline
\end{tabular}

Functional outcome was excellent in 22 cases, good in 8 cases and fair in 2 cases.

\begin{tabular}{|c|c|c|c|}
\hline Side Affected & Males & Females & Total \\
\hline Right & 16 & 8 & $\mathbf{2 4}$ \\
\hline Left & 5 & 3 & $\mathbf{8}$ \\
\hline \multicolumn{4}{|c|}{ Table 7. Side Affected } \\
\hline
\end{tabular}

Right clavicle was affected in 21 patients ( 16 males and 5 females) and left clavicle was affected in 11 patients ( 8 males and 3 females).

\begin{tabular}{|c|c|c|c|}
\hline Union Time & $<\mathbf{1 0}$ wks. & $>\mathbf{1 0}$ wks. & Total \\
\hline No. of patients attained union & $\begin{array}{c}11 \\
(34.37 \%)\end{array}$ & $\begin{array}{c}21 \\
(65.62 \%)\end{array}$ & 32 \\
\hline \multicolumn{3}{|c|}{ Table 8. Union Time } \\
\hline
\end{tabular}

Union time was $<10$ weeks in 11 patients and $>10$ weeks in 21 patients.

\section{DISCUSSION}

Clavicle fractures are a common injury representing approximately $2.6-4 \%$ of adult fractures and approximately $35 \%$ of injuries to the shoulder girdle.

Young males are at risk of clavicle fracture during sports activities when a direct force is applied to the point of the shoulder.

Studies comparing the Kirschner wire fixation and hook plate techniques have shown that the clavicle hook plate has fewer complications and allows earlier mobilisation.

\begin{tabular}{|c|c|c|c|c|c|}
\hline Complications & \begin{tabular}{|c|} 
Present \\
Study
\end{tabular} & $\begin{array}{c}\text { Renger } \\
\text { et } \text { al }^{7}\end{array}$ & \begin{tabular}{|c|} 
Lee \\
et al $^{8}$
\end{tabular} & \begin{tabular}{|c|} 
Tambe \\
et al $^{9}$
\end{tabular} & $\begin{array}{c}\text { Dovit terin } \\
\text { et al }\end{array}$ \\
\hline $\begin{array}{l}\text { Superficial } \\
\text { infection }\end{array}$ & $4.54 \%$ & $4.5 \%$ & & & \\
\hline Implant failure & - & $2.2 \%$ & & & \\
\hline Nonunion & $4.54 \%$ & & $4.3 \%$ & $11.11 \%$ & $3.57 \%$ \\
\hline $\begin{array}{c}\text { Subacromial } \\
\text { osteolysis }\end{array}$ & $13.63 \%$ & $6.8 \%$ & $17 \%$ & $27.77 \%$ & $25 \%$ \\
\hline $\begin{array}{l}\text { Impingement } \\
\text { and pain }\end{array}$ & $32 \%$ & $68 \%$ & & & $32 \%$ \\
\hline
\end{tabular}

\begin{tabular}{|c|c|c|c|c|}
\hline & $\begin{array}{c}\text { Constant } \\
\text { Score } \\
\text { (mean) }\end{array}$ & $\begin{array}{c}\text { Functional } \\
\text { Outcome }\end{array}$ & $\begin{array}{c}\text { Union Rate } \\
\text { (Time) } \\
\text { Average }\end{array}$ & $\begin{array}{c}\text { Mean } \\
\text { Age }\end{array}$ \\
\hline Present study & 97 & Excellent & 12 weeks & 33 \\
\hline Muranatsu et al & 89 & Good & 12 weeks & 47 \\
\hline Renger et al ${ }^{7}$ & 92.4 & Excellent & 20 weeks & 38.4 \\
\hline${\text { Lee et } \mathrm{al}^{8}}^{\mathrm{T}}$ & 91 & Excellent & 16 weeks & 40 \\
\hline Tambe et $\mathrm{al}^{9}$ & 88.5 & Good & & \\
\hline \multicolumn{3}{|c|}{ Table 10. Comparison of Functional Outcome, } \\
Constant Score and Mean Age in Different Studies \\
\hline
\end{tabular}

In this study, road traffic accident is common mode of injury followed by direct injury to shoulder due to fall and fall on outstretched hand. Road traffic accident amount to 16 (50\%) cases; direct injury to shoulder amount to 5 (15.60\%) cases and $11(34.37 \%)$ cases of fall on outstretched hand. In study by Pien-Cheng Liu et al, the clavicle injuries were a result of traffic accidents in 16 patients, slipping incidents in five patients and industrial-related incidents in two patients.

In our study, fracture of clavicle middle third is seen over age range of 18 yrs. to 67 yrs. more common in second and third decade of life, average age was 33 yrs.

A.D. Tambe, ${ }^{9}$ the average age was 40 (range 22-62) years. Renger $\mathrm{RJ}^{7}$ et al, 44 patients, average age 38.4 years (18-66 years). In study by Pien-Cheng Liu et al, clavicle fractures were seen in 16 to 66 yrs. with average age being 41.5 yrs.

In our study, clavicle fractures were common in male than females. Fractures were seen in 24 male (75\%) patients and 8 (25\%) female patients. In study by PIen-Cheng Liu et al, number of males was 16 and number of females 6; which is comparable with our study.

Short-term results and complications (Table 2) during the outpatient clinic follow up, four patients reported pain, 2 patients were having subacromial osteolysis, 1 with nonunion and 1 with superficial wound infection. All fractures except one were clinically and radiologically united. Mid-term results and complications (Table 3), the mean Constant-Murley score was 97 (78-100) a nonunion in one patient was confirmed, radiographically. In two patients, ACJ arthrosis was observed. These patients had no symptoms. Only one of these patients with ACJ arthrosis had suffered impingement symptoms. Lee et $\mathrm{al}^{8}$ encountered subacromial osteolysis $(17 \%)$ and subacromial bursitis (22\%). These complications can be minimised by performing an anatomic fit of the plate during the procedure.

In our study, 3 patients (13.63\%) had ACJ arthrosis, of which one was symptomatic. Only one patient with ACJ arthrosis had suffered impingement without signs of subacromial osteolysis. In light of previous publications about the lateral clavicle fracture, $\mathrm{ACJ}$ arthrosis as well as extraarticular ossification are more likely to be caused by the initial trauma to the joint and the ligaments rather than a complication that can be addressed to the hook plate.

In our study, union time was 12 weeks ranging from 10 to 32 weeks. A nonunion in one patient was confirmed radiographically. $67 \%$ of patients those attained union, mean union time was less than 10 weeks, rest were having mean union time more than 10 weeks ranging upto 32 weeks. Meda PV et al, ${ }^{10} 31$ patients (M:F; 24:7) with a mean age of 49 years (range 25-86 years) were recruited for the study. All the patients achieved clinical and radiological union over a mean of 12 weeks (range 6-18 weeks). Muramatsu et al,11 all fractures eventually achieved solid bony union within 4 
months after surgery. Thirteen patients (87\%) showed hook migration into the acromion. Clinical results were excellent with a mean Constant-Murley score of 89 points at final followup. Lee KW,12 23 patients underwent arthroscopicassisted LCP clavicular hook plate fixation for these fractures. All patients achieved clinical and radiological union over a mean of 4.2 months (range, 3.4-5 months).

Muramatsu et al, 15 consecutive patients with unstable fractures of the distal clavicle (Neer type II) were treated using AO clavicle hook-plates. Clinical results were excellent with a mean Constant-Murley score of 89 points at final followup.

A.D. Tambe et al retrospectively assessed the union and shoulder function following hook plate fixation in 18 patients with Neer type 2 fractures of the lateral end of the clavicle. The average age was 40 (range 22-62) years and the mean followup was 25 (range 6-48) months. The average pain score at rest was 1 (range $0-4$ ) and the average pain score on abduction was 2.2 (range $0-5$ ). The average constant score was 88.5 (range 63-100). Patients were asked to rate their shoulder function; 3 rated it as normal, 11 as nearly normal and 1 as not normal. Hook plate fixation appears to be a valuable method of stabilising Neer type 2 fractures of the clavicle resulting in high union rates and good shoulder function.

Davut Tiren et al performed a study to evaluate the results and long-term effects in use of this plate and performed a retrospective analysis with a mean follow up of 65 months (5.4 years) of 28 consecutive patients with acute displaced lateral clavicle fractures treated with the clavicle hook plate. The Constant-Murley score was 97.

\section{CONCLUSION}

Clavicle hook plate fixation is a better treatment for the displaced lateral clavicle fracture. It facilitates early mobilisation of the shoulder postoperatively and results in a more chances of union and shoulder function.

Operative treatment of patients with displaced lateral clavicle fractures with the hook plate has produced good short term as well as midterm results.

Using this plate may cause impingement and subacromial osteolysis without leading to functional impairment. These complications can be minimised by meticulously adjusting the plate to the individual anatomy with verification under fluoroscopy.

A second operation is needed to remove the plate after fracture consolidation. In the short-term follow up, after plate removal, impingement complaints and the osteolysis disappear.

\section{REFERENCES}

[1] Craig EV, Basamania CJ, Rockwood CA. Fractures of the clavicle. Chapter-11, In: Rockwood CA, Matsen FA, Wirth MA, et al. (eds). The shoulder. $3^{\text {rd }}$ edn. Philadelphia: Saunders 2004:455-519.

[2] Nordqvist A, Petersson C. The incidence of fractures of the clavicle. Clin Orthop Relat Res 1994;300:127-32.

[3] Deafenbaugh MK, Dugdale TW, Staeheli JW, et al. Nonoperative treatment of Neer type-II distal clavicle fractures: a prospective study. Contemp Orthop 1990;20(4):405-13.

[4] Robinson CM, Cairns DA. Primary nonoperative treatment of displaced lateral fractures of the clavicle. J Bone Joint Surg Am 2004;86-A(4):778-82.

[5] Rokito AS, Zuckerman JD, Shaari JM, et al. A comparison of nonoperative and operative treatment of type II distal clavicle fractures. Bull HospJt Dis 20022003;61(1-2):32-9.

[6] Poigenfurst J, Rappold G, Fischer W. Plating of fresh clavicular fractures: results of 122 operations. Injury 1992;23(4):237-41.

[7] Renger RJ, Roukema GR, Reurings JC, et al. The clavicle hook plate for Neer type-II lateral clavicle fractures. J Orthop Trauma 2009;23(8):570-4.

[8] Lee KW, Debski RE, Chen $\mathrm{CH}$, et al. Functional evaluation of the ligaments at the acromioclavicular joint during anteroposterior and superoinferior translation. Am J Sports Med 1997;25(6):858-62.

[9] Tambe AD, Motkur P, Qamar A, et al. Fractures of the distal third of the clavicle treated by hook plating. Int Orthop 2006;30(1):7-10.

[10] Meda PV, Machani B, Sinopidis C, et al. Clavicular hook plate for lateral end fractures- A prospective study. Injury 2006;37(3):277-83.

[11] Muramatsu K, Shigetomi M, Matsunaga T, et al. Use of the AO hook-plate for treatment of unstable fractures of the distal clavicle. Arch Orthop Trauma Surg 2007;127(3):191-4.

[12] Lee KW, Lee SK, Kim KJ, et al. Arthroscopic-assisted locking compression plate clavicular hook fixation for unstable fractures of the lateral end of the clavicle- A prospective study. Int Orthop 2010;34(6):839-45. 